\title{
TWIST1 hypermethylation is observed in pancreatic cancer
}

\author{
MANABU SEN-YO ${ }^{1}$, YUTAKA SUEHIRO ${ }^{2}$, SEIJI KAINO $^{1}$ and ISAO SAKAIDA ${ }^{1}$ \\ Departments of ${ }^{1}$ Gastroenterology and Hepatology and ${ }^{2}$ Oncology and Laboratory Medicine, \\ Yamaguchi University Graduate School of Medicine, Ube, Yamaguchi 755-8505, Japan
}

Received September 4, 2012; Accepted October 9, 2012

DOI: 10.3892/br.2012.25

\begin{abstract}
Despite the growing evidence demonstrating that TWIST1 is a noteworthy tumor biomarker, little is known about the clinical significance of TWIST1 methylation in human primary pancreatic cancer. In the present study, the association of TWIST1 methylation with clinicopathological characteristics was examined in human primary pancreatic cancer. Primary pancreatic cancer specimens and corresponding healthy pancreatic non-tumorous tissues from 33 patients with pancreatic cancer were used. Methylation levels of TWISTI were compared with clinicopathological characteristics. The TWIST1 methylation level was higher in pancreatic cancer compared to corresponding non-neoplastic pancreatic tissues. The mean TWIST1 methylation was $66.7 \%$ for pancreatic cancer tissue and $15.0 \%$ for corresponding nonneoplastic pancreatic tissue $(\mathrm{P}=0.0004)$. These results suggested that TWIST1 methylation is a useful biomarker for the screening of pancreatic cancers. Studies using independent data sets are required to confirm these findings.
\end{abstract}

\section{Introduction}

Given that pancreatic cancer is the fourth most common cause of cancer-related mortality and has the lowest patient survival rate of any solid cancer type $(1,2)$, early diagnosis and therapy remain a major challenge.

Pancreatic cancer has been shown to be epigenetic, since it is a genetic disease characterized by widespread and profound alterations in DNA methylation. TWIST1 is a highly conserved transcription characteristic that belongs to the family of basic helixloop-helix proteins and is involved in embryonic development through the regulation of the migration-invasion program [termed the epithelial-mesenchymal transition (EMT)] during neural crest migration, while regulating mesodermal determination, myogenesis and morphogenesis (3-5). Although growing evidence demonstrates that TWIST1 methylation is a

Correspondence to: Dr Manabu Sen-Yo, Department of Gastroenterology and Hepatology, Yamaguchi University Graduate School of Medicine, 1-1-1 Minami-Kogushi, Ube, Yamaguchi 755-8505, Japan

E-mail:n004uj@yamaguchi-u.ac.jp

Key words: pancreatic cancer, TWIST1, hypermethylation notable tumor biomarker in various tumors (6-9), little is known concerning the clinical significance of TWIST1 methylation in human primary pancreatic cancer. These correlations were investigated in the present study. Results showed that TWISTI is methylated more frequently in pancreatic cancer compared to non-neoplastic pancreatic tissue, providing a new diagnostic marker for pancreatic cancer.

\section{Materials and methods}

Materials. Formalin-fixed, paraffin-embedded primary pancreatic cancer tissues and corresponding non-neoplastic pancreatic tissues from 33 patients who underwent surgical resection between 2004 and 2009 were evaluated. DNA was prepared from cells in microdissected, $5-\mu \mathrm{m}$ histopathological sections, as described previously (9). Clinicopathological characteristics were available for the patients. The mean age of the patients (17 males) was 64.4 years. Eighteen tumors were located in the pancreatic head, 10 in the pancreatic body and 3 in the pancreatic tail. One tumor was stage I, 4 were stage II, 15 were stage III, 7 were stage IVa and 6 were stage IVb (classified according to the classification of pancreatic carcinoma of the Japan Pancreas Society). The study protocol was approved by the Institutional Review Board of Yamaguchi University Graduate School of Medicine. Informed consent was obtained from each patient.

Sodium bisulfite modification of DNA. Bisulfite treatment was performed as reported previously (9). Two micrograms of genomic DNA in $50 \mu \mathrm{l}$ of water were denatured with $5.5 \mu \mathrm{l}$ of $2 \mathrm{M} \mathrm{NaOH}$ at $37^{\circ} \mathrm{C}$ for $10 \mathrm{~min}$, followed by incubation with $30 \mu \mathrm{l}$ of $10 \mathrm{mM}$ hydroquinone and $520 \mu \mathrm{l}$ of $3 \mathrm{M}$ sodium bisulfite $\left(\mathrm{pH} \mathrm{5.0)}\right.$ at $50^{\circ} \mathrm{C}$ for $16 \mathrm{~h}$ in the dark. DNA was then purified with $50 \mu \mathrm{l}$ of water and a DNA Cleanup kit (Promega Corporation, Madison, WI, USA), according to the manufacturer's instructions, incubated with $5.5 \mu \mathrm{l}$ of $3 \mathrm{M} \mathrm{NaOH}$ at room temperature for $5 \mathrm{~min}$, precipitated with $1 \mu \mathrm{l}$ of $20 \mathrm{mg} / \mathrm{ml}$ glycogen, $33 \mu \mathrm{l}$ of $10 \mathrm{M}$ ammonium acetate and $260 \mu \mathrm{l}$ of $100 \%$ ethanol, washed with $70 \%$ ethanol and finally re-suspended in distilled water. DNAs used as positive controls for methylated and unmethylated alleles were SssI methyltransferase-treated placental DNA (New England Biolabs, Ipswich, MA, USA) and lymphocyte DNA, respectively.

KRAS mutations. DNA sequencing was used to evaluate mutations in exon 2 of $K R A S$, as described previously (10). 


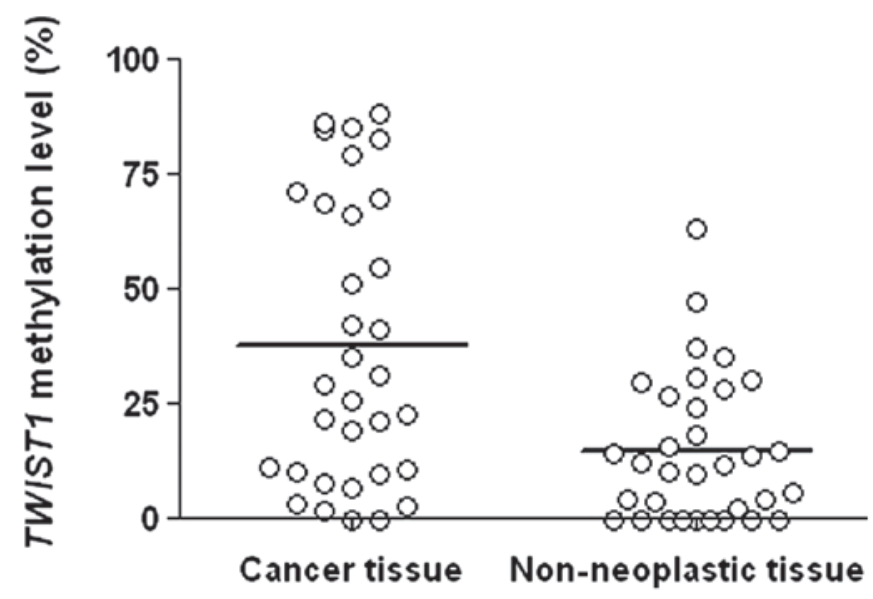

Figure 1. Distribution of TWIST1 methylation in primary pancreatic cancer and non-neoplastic tissues is shown. Each sample is indicated by an open circle. The horizontal lines are the mean level in each group.

Methylation assay. The TWIST1 Combined Bisulfite Restriction Analysis (COBRA) primers were F: 5'-TGTGTA GAAGTTGTTGTTATT-3' and R: 5'-CRAAAAAAACTAT CCTAAC-3' (9). PCR amplification was performed for a total of 40 cycles with an annealing temperature of $55^{\circ} \mathrm{C}$. The PCR product was digested with Bst UI (New England Biolabs). The digested PCR products were separated by electrophoresis on $4 \%$ agarose gels. Digested fragments, which represent methylated DNA, were quantified by densitometry.

\section{Results}

The TWIST1 methylation lever was higher in pancreatic cancer compared to corresponding non-neoplastic pancreatic tissue (Fig. 1). The mean TWIST1 methylation was $66.7 \%$ for pancreatic cancer tissue and $15.0 \%$ for corresponding non-neoplastic pancreatic tissue $(\mathrm{P}=0.0004)$. After setting the cut-off point at $15.0 \%$, which was the mean level of TWIST1 methylation in nonneoplastic pancreatic tissue, the correlations between TWIST1 methylation status and clinicopathological characteristics were studied. No correlations were detected between TWIST1 methylation status in cancer tissue and clinicopathological characteristics (Table I).

\section{Discussion}

The TWIST1 methylation level was higher in pancreatic cancer compared to non-neoplastic pancreatic tissue. To the best of our knowledge, this is the first study on the distinct difference in TWIST1 methylation levels in healthy pancreatic tissues and pancreatic cancer, suggesting a potential for TWIST1 as a biomarker for the early detection of pancreatic cancers using pancreatic juice DNA-based assays.

Hypermethylation of DNA in promoter $\mathrm{CpG}$ islands results in the transcriptional silencing of cancer-related genes (11). In the present study, hypermethylation of TWISTI was observed frequently in pancreatic cancer. However, upregulation of TWIST mRNA in pancreatic cancer has been reported (12). This discrepancy may be due to the lack of a direct correlation between TWIST1 methylation and TWISTI
Table I. Correlations between TWIST1 methylation status and clinicopathological findings in pancreatic cancer patients.

\begin{tabular}{|c|c|c|c|}
\hline \multirow[b]{2}{*}{ Characteristics } & \multicolumn{2}{|c|}{ TWIST1 methylation status } & \multirow[b]{2}{*}{ P-value } \\
\hline & Methylated & Unmethylated & \\
\hline \multicolumn{4}{|l|}{ Age (years) } \\
\hline$>60$ & 12 & 7 & 0.719 \\
\hline$\leq 60$ & 10 & 4 & \\
\hline \multicolumn{4}{|l|}{ Gender } \\
\hline Male & 13 & 4 & 0.282 \\
\hline Female & 9 & 7 & \\
\hline \multicolumn{4}{|c|}{ Histological type $^{\mathrm{b}}$} \\
\hline Well & 7 & 4 & 1.000 \\
\hline Mod-poor & 15 & 7 & \\
\hline \multicolumn{4}{|l|}{ TNM stage $^{c}$} \\
\hline I, II, III & 14 & 7 & 1.000 \\
\hline IVa, IVb & 8 & 4 & \\
\hline \multicolumn{4}{|c|}{ Perineural invasion ${ }^{\mathrm{d}}$} \\
\hline+ & 19 & 8 & 0.375 \\
\hline- & 3 & 3 & \\
\hline \multicolumn{4}{|c|}{ Venous invasion $^{\mathrm{d}}$} \\
\hline+ & 16 & 7 & 0.696 \\
\hline- & 6 & 4 & \\
\hline \multicolumn{4}{|c|}{ Lymphatic invasion $^{\mathrm{d}}$} \\
\hline+ & 20 & 9 & 0.586 \\
\hline- & 2 & 2 & \\
\hline \multicolumn{4}{|l|}{ KRAS mutation } \\
\hline+ & 14 & 8 & 1.000 \\
\hline- & 4 & 3 & \\
\hline
\end{tabular}

${ }^{a}$ Analyzed by the Fisher's test. ${ }^{\text {b} W e l l, ~ w e l l-d i f f e r e n t i a t e d ~ a d e n o c a r c i-~}$ noma; mod-poor, moderately or poorly differentiated adenocarcinoma. ${ }^{\mathrm{c}}$ Classified based on the International Union Against Cancer tumornode-metastasis classification. ${ }^{\mathrm{d}}$ Classified based on the classification of pancreatic carcinoma of the Japan Pancreas Society.

expression in primary colorectal (9) and breast cancers (13). Characteristics other than TWIST1 methylation may also affect TWIST1 expression in pancreatic cancer. TWIST1 expression is regulated by hypoxia, a common characteristic in solid cancers, in an HIF-1 $\alpha$ - and HIF- $2 \alpha$-dependent manner (14,15). Alternately, TWIST1 promoter methylation might be an early event, preceding compensatory TWIST1 overexpression (13).

In conclusion, increasing evidence has demonstrated that TWIST1 exhibits a unique characteristic as a tumor marker. Since TWIST1 methylation levels are higher in pancreatic cancers compared to corresponding healthy pancreatic tissues, TWIST1 methylation may be a feasible epigenetic marker for the detection of pancreatic cancer, using a pancreatic juice DNA test. Confirmatory studies using independent data sets are required to support these findings. 


\section{References}

1. Warshaw AL and Fernandez-del Castillo C: Pancreatic carcinoma. N Engl J Med 326: 455-465, 1992.

2. Niederhuber JE, Brennan MF and Menck HR: The National Cancer Data Base report on pancreatic cancer. Cancer 76: 1671-1677, 1995.

3. Hebrok M, Wertz K and Fuchtbauer EM: M-twist is an inhibitor of muscle differentiation: Dev Biol 165: 537-544, 1994.

4. Chen ZF and Behringer RR: Twist is required in head mesenchyme for cranial neural tube morphogenesis. Genes Dev 9: 686-699, 1995.

5. Thiery JP: Epithelial-mesenchymal transitions in tumour progression. Nat Rev Cancer 2: 442-454, 2002.

6. Selamat SA, Galler JS, Joshi AD, et al: DNA methylation changes in atypical adenomatous hyperplasia, adenocarcinoma in situ, and lung adenocarcinoma. PloS One 6: e21443, 2011.

7. Missaoui N, Hmissa S, Trabelsi A, et al: Promoter hypermethylation of CDH13, DAPK1 and TWIST1 genes in precancerous and cancerous lesions of the uterine cervix. Pathol Res Prac 207: 37-42, 2011.

8. Renard I, Joniau S, van Cleynenbreugel B, et al: Identification and validation of the methylated TWIST1 and NID2 genes through real-time methylation-specific polymerase chain reaction assays for the noninvasive detection of primary bladder cancer in urine samples. Eur Urol 58: 96-104, 2010.
9. Okada T, Suehiro Y, Ueno K, et al: TWIST1 hypermethylation is observed frequently in colorectal tumors and its overexpression is associated with unfavorable outcomes in patients with colorectal cancer. Genes Chromosomes Cancer 49: 452-462, 2010.

10. Suehiro Y, Wong CW, Chirieac LR, et al: Epigenetic-genetic interactions in the APC/WNT, RAS/RAF, and P53 pathways in colorectal carcinoma. Clin Cancer Res 14: 2560-2569, 2008.

11. Santini V, Kantarjian HM and Issa JP: Changes in DNA methylation in neoplasia: pathophysiology and therapeutic implications. Ann Inter Med 134: 573-586, 2001

12. Ohuchida K, Mizumoto K, Ohhashi S, et al: Twist, a novel oncogene, is upregulated in pancreatic cancer: clinical implication of Twist expression in pancreatic juice. Int J Cancer 120: 1634-1640, 2007

13. Gort EH, Suijkerbuijk KP, Roothaan SM, et al: Methylation of the TWIST1 promoter, TWIST1 mRNA levels, and immunohistochemical expression of TWIST1 in breast cancer. Cancer Epidemiol Biomarkers Prev 17: 3325-3330, 2008.

14. Gort EH, van Haaften G, Verlaan I, et al: The TWIST1 oncogene is a direct target of hypoxia-inducible factor-2alpha. Oncogene 27: $1501-1510,2008$

15. Yang MH, Wu MZ, Chiou SH, et al: Direct regulation of TWIST by HIF-1alpha promotes metastasis. Nat Cell Biol 10: 295-305, 2008. 